\title{
The Cold Air Incursion Prediction Based on the Behavioral Model of Opening/Closing a Door of Classroom Established by Matlab
}

\author{
Zi Ouyang ${ }^{a}$, Haorui Zhang, Yike Chen, Haoyu Chao and Weiwei Yu \\ Xi'an Jiao Tong University, 28 West Xianning Rd. Beilin District, Xi'an 710049, China \\ aouyangzi002@163.com
}

Keywords: Computational methods. Convection. Thermal management. The behavioral model of opening/closing a door. MATLAB. Cold air incursion prediction.

Abstract. Through our observation of the classmates' behavior when entering or leaving the classroom, we find that it is more probable that they will keep the door close than leave it open when the door is already close. And the larger the number of classmates entering or leaving the classroom per unit time is, the less probability that they will close the door. Additionally, if the door has been kept open for a period of time, one or two classmates will close the door with initiative. Then the classmates having seen their behaviors will also have the consciousness of closing the door. So we use the software MATLAB to establish the mathematical model of classmates' closing or opening the door when entering or leaving the classroom on the base of our observation. Furthermore, since the cold air incursion is related to the state whether the door is close, we also use our model to predict about the heat loss from the cold air incursion.

\section{Introduction}

Introducing Phenomenon. Our politics teacher requires that we investigate uncivilized phenomenon, so we investigate the classmates' behavior of opening/closing a door of the classroom when they enter or leave this classroom. During the course of our observation and investigation, the data collection can be completed by using the video capture method. Fig. 1 shows some main photographs obtained by using clipping video.

Analyzing Phenomenon. Through our observation of the classmates' behavior when entering or leaving the classroom, we find that it is more probable that they will keep the door close than leave it open when the door is already close. And the larger the number of classmates entering or leaving the classroom per unit time is, the less probability that will close the door. Additionally, if the door has been kept open for a period of time, one or two classmates will close the door with initiative. Then the classmates having seen their behaviors will also have the consciousness of closing the door.
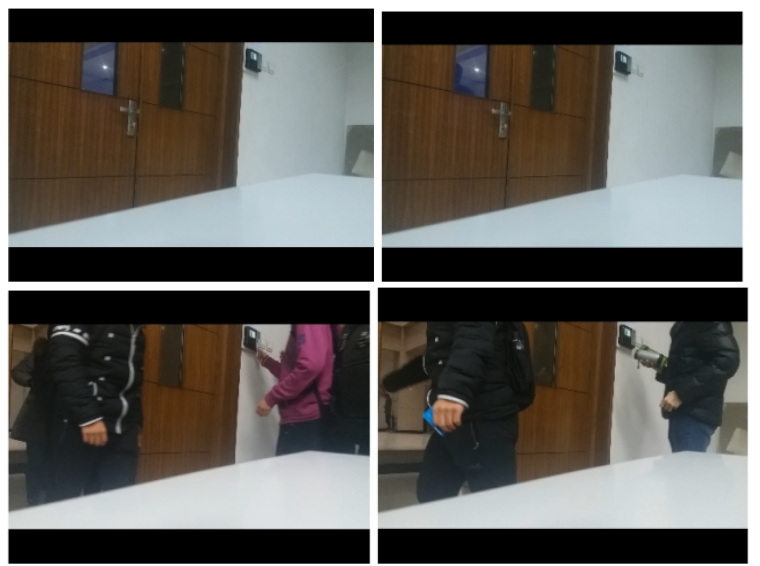

Fig. 1 Main photographs obtained by using clipping video. 


\section{Establishing Model and Making Mathematical Experiment}

Establishing Model. We establish the following mathematical model in order to provide a more concrete analysis on this phenomenon, and also to promote the method of the research on uncivilized behavior.

In the initial stages, for most of classmates when entering or leaving the classroom, we suppose that

(1) $\mathrm{p}_{10}$ is the probability of closing a door not been opened yet;

(2) $\mathrm{p}_{20}$ is the probability of closing a door opened already;

(3) $\mathrm{p}(\mathrm{n})$ is the probability of the door closed when the nth person enters this classroom;

(4) $p_{1}$, is the probability of closing a door when the (n-1) th person enters this classroom, and at the time the door of this classroom is closed still. But $\mathrm{p}_{2}$ is the probability of closing a door opened already when the (n-1) th person enters the classroom.

Then, the following relationship is obtained

$$
\mathrm{p}(\mathrm{n})=\mathrm{p}_{1} \times \mathrm{p}(\mathrm{n}-1)+\mathrm{p}_{2} \times(1-\mathrm{p}(\mathrm{n}-1))
$$

And, because both $\mathrm{p}_{1}$ and $\mathrm{p}_{2}$ decrease with increase on the flow rate of people, we assume that the flow rate of people follows normal distributions for time, as follows:

$$
f(t)=a_{1} \times \exp \left(-\left(\frac{\left(t-b_{1}\right)}{c_{1}}\right)^{2}\right)
$$

where $a_{1}, b_{1}$ and $c_{1}$ are constants. So, the probability of closing a door at time " $t$ " may be fitted with index equations, we have

$$
\mathrm{p}_{1}=\mathrm{p}_{10} \times \exp (-\mathrm{kf}(\mathrm{t}))
$$

and

$$
\mathrm{p}_{2}=\mathrm{p}_{20} \times \exp (-\mathrm{kf}(\mathrm{t}))
$$

where the symbol, $\mathrm{k}$ denotes constant.

Next, the probability of the door is closed by the nth person, which can be solved by using the following equations (Note: $\mathrm{f}\left(\mathrm{t}_{0}\right)$ should be close to zero as far as possible, $\mathrm{t}_{0}$ is the initial time).

$$
\begin{aligned}
& \int_{\mathrm{t}_{0}}^{\mathrm{t}} \mathrm{f}(\mathrm{t}) \mathrm{dt}=\mathrm{n} \\
& \text { and } \\
& \mathrm{p}_{1}=\mathrm{p}_{10} \times \exp (-\mathrm{kf}(\mathrm{t})) \\
& \mathrm{p}_{2}=\mathrm{p}_{20} \times \exp (-\mathrm{kf}(\mathrm{t}))
\end{aligned}
$$

\section{Mathematical Experiment Assumptions.}

(1) There are altogether $\mathrm{N}$ classmates.

(2) The symbol $p_{0}$ denotes the proportion of classmates who are able to close the door consciously. $\mathrm{p}_{0}$ represents these classmates sitting at the door and feeling chilly, and also those sitting at the door before then, have been influenced by the conscious behavior of closing the door. Obviously, they are different from most of classmates, they will close the door based on the above two reasons mentioned, the probability of closing a door is higher than most of other classmates.

(3) The behavioral model gives the assumption that the probability of closing the door equals to "1" when the classmate mentioned above appears every time. Then, the boundary probability, $\mathrm{q}$ is also assumed, additionally, the door is considered to be open when $\mathrm{p}<\mathrm{q}$, on the contrary, the door is close.

Based on the model established and assumptions above, we make mathematical experiment by introducing MATLAB.

Mathematical Experiment Results and Conclusions. According to our mathematical model, it is easy to know that the variable influencing on generation and diffusion of uncivil behaviors can be given by

$$
\mathrm{p}_{30}=\mathrm{p}_{10}+\mathrm{p}_{20}
$$


The symbol $\mathrm{p}_{30}$ is proportion value of person who can close the door without anyone telling them to do it. The $\mathrm{p}_{0}$ mentioned above represents these kinds of persons can close the door consciously. The two variables, $\mathrm{p}_{30}$ and $\mathrm{p}_{0}$ seem to be the same, but they have essential difference.

The symbol $\mathrm{p}_{30}$ represents the behavior of closing a door of people, which is an absolute spontaneous behavior with independence and specificity. But, $\mathrm{p}_{0}$ expresses that the behavior of closing a door tends to a behavior "simulated", namely the activity according with live in group, is influenced by other's behavior.

In general, we may not discriminate between $\mathrm{p}_{30}$ and $\mathrm{p}_{0}$, or, the differences between $\mathrm{p}_{30}$ and $\mathrm{p}_{0}$ are considered to have not an influence on outputting results. But, we give a certain condition, i.e., we give an influence of others on the behavior model, at this time, $\mathrm{p}_{0}>\mathrm{p}_{30}$, the behavior of closing a door will occur easily. So, we have sought a solution to the problem.

In this paper, the mathematical experiment results highlight the importance of the environmental influences, and the environmental influences are the behavior of others, also can be the supervision from outside, for example, someone stands nearer to the door and reminds him or her to close the door once in a while.

Increase in the value of the $\mathrm{p}_{30}$ remains to heighten the quality of everyone and is also a fundamental solution, but is slower than increase in the value of the $\mathrm{p}_{0}$. By contrast, it is easier to increase the valve of the $\mathrm{p}_{0}$.

\section{Cold Air Incursion Prediction}

When the door is open, which will lead to energy consumption, because of the natural convection resulted from the difference of air temperature between indoor and outdoor, for example, the cold air infiltration through the door of heating room in the winter. In this paper, the mathematical model is established to calculate the cold air incursion and thermal dissipation preliminarily.

Geometric Model. In this paper, the size of the door is 2 meters high, $\mathrm{H}=2 \mathrm{~m}, 1.4$ meters wide, $\mathrm{W}=2 \times 0.7=1.4 \mathrm{~m}$. Fig. 2 shows the geometric model of the door opened. And the angle displacement, $\theta_{1}$ and $\theta_{2}$ also denote the open degree of door illustrated in Fig. 2.

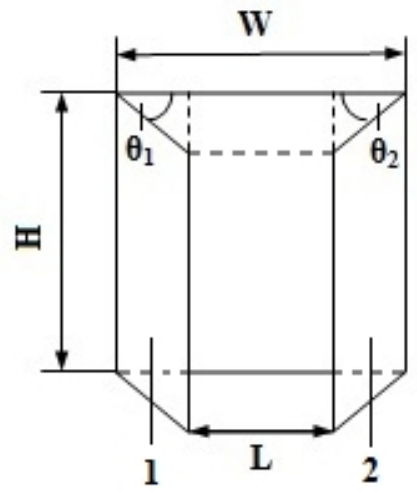

1-door page 2-door page

Fig. 2 Illustration of geometric model of the open double page door.

Cold Air Incursion Mathematical Model. The cold air incursion under consideration is the sum, G, as follows

$\mathrm{G}=\mathrm{G}_{1}+\mathrm{G}_{2}$

where the symbols $G_{1}$ and $G_{2}$ are the cold air incursion from the front and top of the open door as shown in Fig. 3, respectively. 


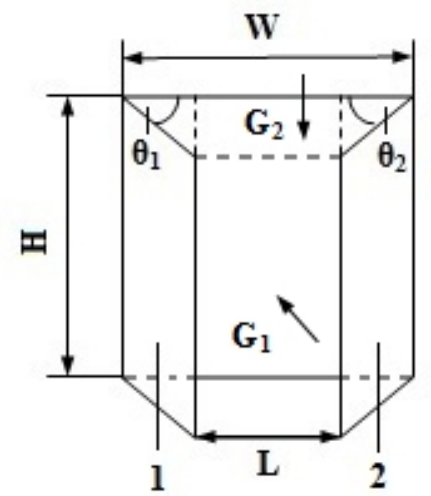

Fig. 3 Illustration of cold air incursion from the front and top of the open door, $G_{1}$ and $G_{2}$.

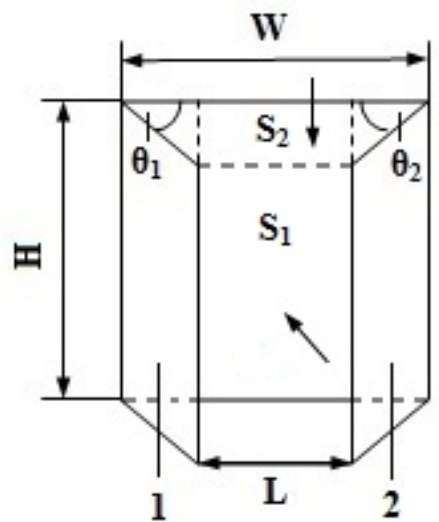

Fig.4 Illustration of cross-sectional area of the cold air incursion from the front and top of the open door, $\mathrm{S}_{1}$ and $\mathrm{S}_{2}$.

The total cross-sectional of area of the cold air incursion under consideration can be expressed as $\mathrm{S}=\mathrm{S}_{1}+\mathrm{S}_{2}$

where the symbols $S_{1}$ and $S_{2}$ are the cross-sectional area of the cold air incursion from the front and top of the open door as shown in Fig.4, respectively.

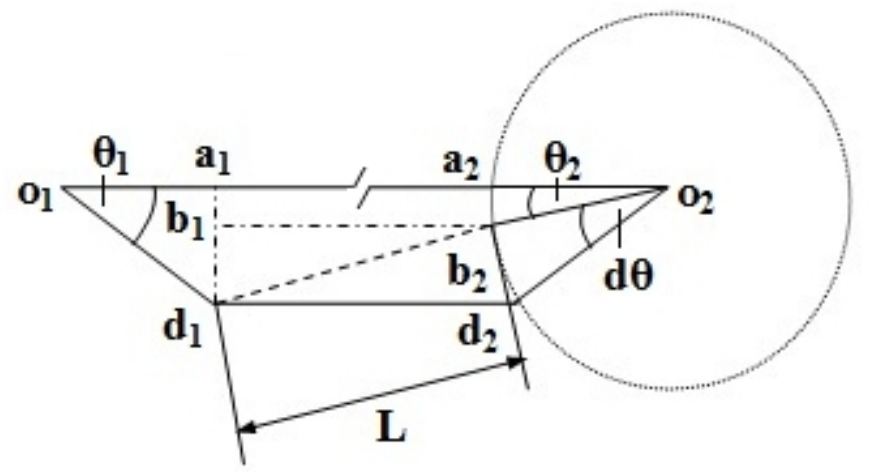

Fig. 5 Illustration of geometrical model of the top of the door being open $\left(\theta_{1} \neq \theta_{2}\right)$.

Fig.5 shows the geometrical model of the open door, $\mathrm{o}_{1} \mathrm{o}_{2}=W$. Supposing, $\mathrm{a}_{1} \mathrm{a}_{2}=\Delta x, \mathrm{~b}_{1} \mathrm{~d}_{1}=\Delta \mathrm{y}$, and $\theta_{1}=\theta_{2}+\mathrm{d} \theta$, then

$$
\Delta \mathrm{x}=\mathrm{W}-\frac{\mathrm{W}}{2} \times \cos \theta_{1}-\frac{\mathrm{W}}{2} \times \cos \theta_{2}=\mathrm{W}-\frac{\mathrm{W}}{2} \times \cos \left(\theta_{2}+\mathrm{d} \theta\right)-\frac{\mathrm{W}}{2} \times \cos \theta_{2}
$$




$$
\Delta \mathrm{y}=\frac{\mathrm{W}}{2} \times \sin \theta_{1}-\frac{\mathrm{W}}{2} \times \sin \theta_{2}=\frac{\mathrm{W}}{2} \times \sin \left(\theta_{2}+\mathrm{d} \theta\right)-\frac{\mathrm{W}}{2} \times \sin \theta_{2}
$$

and

$$
\mathrm{L}=\sqrt{\Delta \mathrm{x}^{2}+\Delta \mathrm{y}^{2}}
$$

From Fig. 4, the cross-sectional area of the cold air incursion from the front of the open door, $\mathrm{S}_{1}$, is then

$\mathrm{S}_{1}=\mathrm{L} \times \mathrm{H}$

In particular, letting $\mathrm{d} \theta=0$, and $\theta_{1}=\theta_{2}=\theta$, the geometric size, $\mathrm{L}$ takes the following form.

$\mathrm{L}=\sqrt{\Delta \mathrm{x}^{2}}=\Delta \mathrm{x}=\mathrm{W}-\mathrm{W} \cos \theta=(1-\cos \theta) \mathrm{W}$

Hence,

$\mathrm{S}_{1}=(\mathrm{W}-\mathrm{W} \cos \theta) \times \mathrm{H}=(1-\cos \theta) \mathrm{W} \times \mathrm{H}$

The cold air incursion from the front of the open door, $\mathrm{G}_{1}$ is

$\mathrm{G}_{1}=\mathrm{v}_{\mathrm{wl}} \mathrm{S}_{1}$

where $\mathrm{v}_{\mathrm{w} 1}$ represents the velocity of cold air incursion from the front of the open door. Refer to Fig.4 and Fig.5, the top cold air flow area $S_{2}$ can be written as

$$
\begin{aligned}
\mathrm{S}_{2} & =\mathrm{S}_{\mathrm{O}_{1} \mathrm{a}_{1} \mathrm{~b}_{1}}+\mathrm{S}_{\mathrm{a}_{1} \mathrm{a}_{2} \mathrm{~b}_{1} \mathrm{~b}_{2}}+\mathrm{S}_{\mathrm{O}_{2} \mathrm{a}_{2} \mathrm{~b}_{2}}+\mathrm{S}_{\mathrm{b}_{1} \mathrm{~b}_{2} \mathrm{~d}_{1}} \\
& =\frac{1}{2} \times \frac{\mathrm{W}}{2} \cos \theta_{1} \times \frac{\mathrm{W}}{2} \sin \theta_{1}+\left(\mathrm{W}-\frac{\mathrm{W}}{2} \cos \theta_{1}-\frac{\mathrm{W}}{2} \cos \theta_{2}\right) \times \frac{\mathrm{W}}{2} \sin \theta_{2} \\
+ & \frac{1}{2} \times \frac{\mathrm{W}}{2} \cos \theta_{2} \times \frac{\mathrm{W}}{2} \sin \theta_{2}+\frac{1}{2} \times\left(\mathrm{W}-\frac{\mathrm{W}}{2} \cos \theta_{1}-\frac{\mathrm{W}}{2} \cos \theta_{2}\right) \times\left(\frac{\mathrm{W}}{2} \sin \theta_{1}-\frac{\mathrm{W}}{2} \sin \theta_{2}\right)
\end{aligned}
$$

In particular, with $\theta_{1}=\theta_{2}=\theta, S_{2}$ can be reduce to

$$
\begin{aligned}
\mathrm{S}_{2} & =\frac{1}{2} \times\left(\mathrm{W}-\left(2 \times \frac{\mathrm{W}}{2} \cos \theta\right)+\mathrm{W}\right) \times \frac{\mathrm{W}}{2} \sin \theta \\
& =\frac{1}{2} \times(2 \mathrm{~W}-\mathrm{W} \cos \theta) \times \frac{\mathrm{W}}{2} \sin \theta=\left(\mathrm{W}-\frac{\mathrm{W}}{2} \cos \theta\right) \times \frac{\mathrm{W}}{2} \sin \theta=(2-\cos \theta) \sin \theta \times \frac{\mathrm{W}^{2}}{4}
\end{aligned}
$$

The cold air incursion from the top of the open door, $\mathrm{G}_{2}$, in $\mathrm{m}^{3} / \mathrm{s}$, is

$$
\mathrm{G}_{2}=\mathrm{v}_{\mathrm{w} 2} \mathrm{~S}_{2}
$$

where the symbol $\mathrm{v}_{\mathrm{w} 2}$ represents the velocity of cold air flow from the top of door.

Calculation Results of Cold Air Incursion. Let $\theta_{1}=\theta_{2}=\theta=\pi / 6, \pi / 4, \pi / 3$, respectively, and $\mathrm{v}_{\mathrm{w} 1}=$ $\mathrm{v}_{\mathrm{w} 2}=1 \mathrm{~m} / \mathrm{s}$, the values of $\mathrm{S}_{1}, \mathrm{~S}_{2}$, and $\mathrm{G}_{1}, \mathrm{G}_{2}$ are calculated, the calculating date are listed in Table 1 . Additionally, we evaluate the total cross-sectional area of the cold air incursion, $\mathrm{S}$, and the total cold air incursion, $\mathrm{G}$, which are also given in the Table 1 .

Table $1 \mathrm{~S}$ and $\mathrm{G}$ of the open door for $\mathrm{v}_{\mathrm{w} 1}=\mathrm{v}_{\mathrm{w} 2}$ (Let $\left.\mathrm{v}_{\mathrm{w} 1}=\mathrm{v}_{\mathrm{w} 2}=1 \mathrm{~m} / \mathrm{s}\right)$.

\begin{tabular}{cccccccccc}
\hline $\begin{array}{c}\theta_{1} \\
(\mathrm{rad})\end{array}$ & $\begin{array}{c}\theta_{2} \\
(\mathrm{rad})\end{array}$ & $\begin{array}{c}\mathrm{S}_{1} \\
\left(\mathrm{~m}^{2}\right)\end{array}$ & $\begin{array}{c}\mathrm{V}_{\mathrm{w} 1} \\
(\mathrm{~m} / \mathrm{s})\end{array}$ & $\begin{array}{c}\mathrm{G}_{1} \\
\left(\mathrm{~m}^{3} / \mathrm{s}\right)\end{array}$ & $\begin{array}{c}\mathrm{S}_{2} \\
\left(\mathrm{~m}^{2}\right)\end{array}$ & $\begin{array}{c}\mathrm{v}_{\mathrm{w} 2} \\
(\mathrm{~m} / \mathrm{s})\end{array}$ & $\begin{array}{c}\mathrm{G}_{2} \\
\left(\mathrm{~m}^{3} / \mathrm{s}\right)\end{array}$ & $\begin{array}{c}\mathrm{S} \\
\left(\mathrm{m}^{2}\right)\end{array}$ & $\begin{array}{c}\mathrm{G} \\
\left(\mathrm{m}^{3} / \mathrm{s}\right)\end{array}$ \\
\hline$\pi / 6$ & $\pi / 6$ & 0.3751 & 1 & 0.3751 & 0.2778 & 1 & 0.2778 & 0.6529 & 0.6529 \\
$\pi / 4$ & $\pi / 4$ & 0.8201 & 1 & 0.8201 & 0.4480 & 1 & 0.4480 & 1.2681 & 1.2681 \\
$\pi / 3$ & $\pi / 3$ & 1.4 & 1 & 1.4 & 0.6365 & 1 & 0.6365 & 2.0365 & 2.0365 \\
\hline
\end{tabular}

Table 1 shows $S_{1}$ increases with increasing $\theta_{1}$ from $\pi / 6$ to $\pi / 3$, so $G_{1}$ increases. As such, $G_{2}$ also increases with increasing $S_{2}$. From Table 1, we know that $S_{1}$ is about $0.4 \mathrm{~m}^{2}, 0.8 \mathrm{~m}^{2}$ and $1.4 \mathrm{~m}^{2}$ for the angular rotation $\theta_{1}, \pi / 6, \pi / 4$ and $\pi / 3$, respectively. $S_{2}$ is about $0.3 \mathrm{~m}^{2}, 0.4 \mathrm{~m}^{2}$ and $0.6 \mathrm{~m}^{2}$ for the angular rotation $\theta_{2}, \pi / 6, \pi / 4$ and $\pi / 3$, respectively. So the results illustrate that decreasing $\theta_{1}$ and $\theta_{2}$ can reduce the cold air incursion.

Furthermore, based on the date in the Table 1, we can also calculate that the average value of increasing $\mathrm{G}_{1}, \Delta \mathrm{G}_{1 \text {,average }} \approx 0.5 \mathrm{~m}^{3} / \mathrm{s}$ when $\theta_{1}$ and $\theta_{2}$ are raised, and the increasing value, $\Delta \theta_{1}=\Delta \theta_{2}=\pi / 12$, 
the average value of increasing of $\mathrm{G}_{2}, \Delta \mathrm{G}_{2, \text { average }} \approx 0.25 \mathrm{~m}^{3} / \mathrm{s}$. That means $\mathrm{G}=\mathrm{G}_{1}+\mathrm{G}_{2}$, is more affected by the increasing of $G_{1}$. It is clear that the growth rate of $S_{1}$ is higher than the one of $S_{2}$. Accordingly, the growth rate of $\mathrm{G}_{1}$ is also higher than the one of $\mathrm{G}_{2}$. From the calculating results shown in Table 1, we can see that the growth rate of $S$ is the same as the one of $G$ when we give $\mathrm{v}_{\mathrm{wl}}=\mathrm{v}_{\mathrm{w} 2}=1 \mathrm{~m} / \mathrm{s}$. Thus the above results also prove that decreasing $\theta_{1}$ and $\theta_{2}$ can reduce the cold air incursion.

According to the basic principle of natural convection, the velocity of cold air flow from the top of the open door is different to the one from the front of the open door, for ordinary heating room, for example, our classroom. In normal conditions, $\mathrm{v}_{\mathrm{w} 1}>\mathrm{v}_{\mathrm{w} 2}$, hence, we let $\mathrm{v}_{\mathrm{w} 2}=0.5 \mathrm{~m} / \mathrm{s}$, and $\mathrm{v}_{\mathrm{w} 2} / \mathrm{v}_{\mathrm{w} 1}=1 / 2$. Then $\mathrm{S}$ and $\mathrm{G}$ are calculated further, and the results are shown in Table 2. The data in the Table 2 shows the reduction of growth rate of $G_{2}$ is about $0.1 \mathrm{~m}^{3} / \mathrm{s}, 0.2 \mathrm{~m}^{3} / \mathrm{s}$ and $0.3 \mathrm{~m}^{3} / \mathrm{s}$ for the angular rotation $\theta_{2}, \pi / 6, \pi / 4$ and $\pi / 3$, respectively. And for the total cold air incursion, $\mathrm{G}$, its growth rate also reduces similarly.

Table $2 \mathrm{~S}$ and $\mathrm{G}$ of the open door for $\mathrm{v}_{\mathrm{w} 1} \neq \mathrm{v}_{\mathrm{w} 2}\left(\right.$ Let $\left.\mathrm{v}_{\mathrm{w} 1}>\mathrm{v}_{\mathrm{w} 2}, \mathrm{v}_{\mathrm{w} 2} / \mathrm{v}_{\mathrm{w} 1}=1 / 2\right)$.

\begin{tabular}{cccccccccc}
\hline $\begin{array}{c}\theta_{1} \\
(\mathrm{rad})\end{array}$ & $\begin{array}{c}\theta_{2} \\
(\mathrm{rad})\end{array}$ & $\begin{array}{c}\mathrm{S}_{1} \\
\left(\mathrm{~m}^{2}\right)\end{array}$ & $\begin{array}{c}\mathrm{V}_{\mathrm{w} 1} \\
(\mathrm{~m} / \mathrm{s})\end{array}$ & $\begin{array}{c}\mathrm{G}_{1} \\
\left(\mathrm{~m}^{3} / \mathrm{s}\right)\end{array}$ & $\begin{array}{c}\mathrm{S}_{2} \\
\left(\mathrm{~m}^{2}\right)\end{array}$ & $\begin{array}{c}\mathrm{V}_{\mathrm{w} 2} \\
(\mathrm{~m} / \mathrm{s})\end{array}$ & $\begin{array}{c}\mathrm{G}_{2} \\
\left(\mathrm{~m}^{3} / \mathrm{s}\right)\end{array}$ & $\begin{array}{c}\mathrm{S} \\
\left(\mathrm{m}^{2}\right)\end{array}$ & $\begin{array}{c}\mathrm{G} \\
\left(\mathrm{m}^{3} / \mathrm{s}\right)\end{array}$ \\
\hline$\pi / 6$ & $\pi / 6$ & 0.3751 & 1 & 0.3751 & 0.2778 & 0.5 & 0.1389 & 0.6529 & 0.5140 \\
$\pi / 4$ & $\pi / 4$ & 0.8201 & 1 & 0.8201 & 0.4480 & 0.5 & 0.2240 & 1.2681 & 1.0441 \\
$\pi / 3$ & $\pi / 3$ & 1.4 & 1 & 1.4 & 0.6365 & 0.5 & 0.3183 & 2.0365 & 1.7183 \\
\hline
\end{tabular}

Calculating Heat Loss. Let us evaluate the heat loss due to cold air incursion using date in Table1 and Table 2. The expression for the heat $\mathrm{Q}, \mathrm{kW}$, due to the cold air incursion loss, can be written as

$\mathrm{Q}=\rho \mathrm{Gc} \Delta \mathrm{t}_{1}$

where let the density of air, $\rho=1.29 \mathrm{~kg} / \mathrm{m}^{3}$, the specific heat capacity, $c=10^{3} \mathrm{~J} /(\mathrm{kg} \cdot \square)$, and the temperature difference of the cold and hot air $\Delta \mathrm{t}_{1}=1 \square$. The heat loss from the cold air incursion of the open door is calculated and shown in Table 3 with $\mathrm{v}_{\mathrm{w} 2}=1 \mathrm{~m} / \mathrm{s}$, Table 4 with $\mathrm{v}_{\mathrm{w} 2}=0.5 \mathrm{~m} / \mathrm{s}$.

Table 3 Heat loss from the open door (Let $\mathrm{v}_{\mathrm{w} 2}=1 \mathrm{~m} / \mathrm{s}$ ).

\begin{tabular}{cccccccccc}
\hline $\begin{array}{c}\theta_{1} \\
(\mathrm{rad})\end{array}$ & $\begin{array}{c}\theta_{2} \\
(\mathrm{rad})\end{array}$ & $\begin{array}{c}\mathrm{S}_{1} \\
\left(\mathrm{~m}^{2}\right)\end{array}$ & $\begin{array}{c}\mathrm{v}_{\mathrm{w} 1} \\
(\mathrm{~m} / \mathrm{s})\end{array}$ & $\begin{array}{c}\mathrm{S}_{2} \\
\left(\mathrm{~m}^{2}\right)\end{array}$ & $\begin{array}{c}\mathrm{V}_{\mathrm{w} 2} \\
(\mathrm{~m} / \mathrm{s})\end{array}$ & $\begin{array}{c}\mathrm{S} \\
\left(\mathrm{m}^{2}\right)\end{array}$ & $\begin{array}{c}\mathrm{G} \\
\left(\mathrm{m}^{3} / \mathrm{s}\right)\end{array}$ & $\begin{array}{c}\Delta \mathrm{t}_{1} \\
\left({ }^{\circ} \mathrm{C}\right)\end{array}$ & $\begin{array}{c}\mathrm{Q} \\
(\mathrm{kW})\end{array}$ \\
\hline$\pi / 6$ & $\pi / 6$ & 0.3751 & 1 & 0.2778 & 1 & 0.6529 & 0.6529 & 1 & 0.842 \\
$\pi / 4$ & $\pi / 4$ & 0.8201 & 1 & 0.4480 & 1 & 1.2681 & 1.2681 & 1 & 1.636 \\
$\pi / 3$ & $\pi / 3$ & 1.4 & 1 & 0.6365 & 1 & 2.0365 & 2.0365 & 1 & 2.627 \\
\hline
\end{tabular}

Table 4 Heat loss from the open door $\left(\right.$ Let $\left.\mathrm{v}_{\mathrm{w} 2}=0.5 \mathrm{~m} / \mathrm{s}\right)$.

\begin{tabular}{cccccccccc}
\hline $\begin{array}{c}\theta_{1} \\
(\mathrm{rad})\end{array}$ & $\begin{array}{c}\theta_{2} \\
(\mathrm{rad})\end{array}$ & $\begin{array}{c}\mathrm{S}_{1} \\
\left(\mathrm{~m}^{2}\right)\end{array}$ & $\begin{array}{c}\mathrm{V}_{\mathrm{w} 1} \\
(\mathrm{~m} / \mathrm{s})\end{array}$ & $\begin{array}{c}\mathrm{S}_{2} \\
\left(\mathrm{~m}^{2}\right)\end{array}$ & $\begin{array}{c}\mathrm{V}_{\mathrm{w} 2} \\
(\mathrm{~m} / \mathrm{s})\end{array}$ & $\begin{array}{c}\mathrm{S} \\
\left(\mathrm{m}^{2}\right)\end{array}$ & $\begin{array}{c}\mathrm{G} \\
\left(\mathrm{m}^{3} / \mathrm{s}\right)\end{array}$ & $\begin{array}{c}\Delta \mathrm{t}_{1} \\
\left({ }^{\circ} \mathrm{C}\right)\end{array}$ & $\begin{array}{c}\mathrm{Q} \\
(\mathrm{kW})\end{array}$ \\
\hline$\pi / 6$ & $\pi / 6$ & 0.3751 & 1 & 0.2778 & 0.5 & 0.6529 & 0.5140 & 1 & 0.663 \\
$\pi / 4$ & $\pi / 4$ & 0.8201 & 1 & 0.4480 & 0.5 & 1.2681 & 1.0441 & 1 & 1.347 \\
$\pi / 3$ & $\pi / 3$ & 1.4 & 1 & 0.6365 & 0.5 & 2.0365 & 1.7183 & 1 & 2.217 \\
\hline
\end{tabular}

Table 5 Influence of the change in $\mathrm{v}_{\mathrm{w} 2}$ on the cold air incursion and heat loss.

\begin{tabular}{ccccccccc}
\hline $\begin{array}{c}\theta_{1} \\
(\mathrm{rad})\end{array}$ & $\begin{array}{c}\theta_{2} \\
(\mathrm{rad})\end{array}$ & $\begin{array}{c}\Delta \mathrm{v}_{\mathrm{w} 2} \\
(\mathrm{~m} / \mathrm{s})\end{array}$ & $\begin{array}{c}\mathrm{G}^{\prime} \\
\left(\mathrm{m}^{3} / \mathrm{s}\right)\end{array}$ & $\begin{array}{c}\mathrm{G}^{\prime \prime} \\
\left(\mathrm{m}^{3} / \mathrm{s}\right)\end{array}$ & $\begin{array}{c}\Delta \mathrm{G} \\
\left(\mathrm{m}^{3} / \mathrm{s}\right)\end{array}$ & $\begin{array}{c}\mathrm{Q}^{\prime} \\
(\mathrm{kW})\end{array}$ & $\begin{array}{c}\mathrm{Q}^{\prime \prime} \\
(\mathrm{kW})\end{array}$ & $\begin{array}{c}\Delta \mathrm{Q} \\
(\mathrm{kW})\end{array}$ \\
\hline$\pi / 6$ & $\pi / 6$ & 0.5 & 0.6529 & 0.5140 & 0.1389 & 0.842 & 0.663 & 0.179 \\
$\pi / 4$ & $\pi / 4$ & 0.5 & 1.2681 & 1.0441 & 0.2240 & 1.636 & 1.347 & 0.289 \\
$\pi / 3$ & $\pi / 3$ & 0.5 & 2.0365 & 1.7183 & 0.3182 & 2.627 & 2.217 & 0.410 \\
\hline
\end{tabular}

Table 5 gives the influence of $\mathrm{v}_{\mathrm{w} 2}$ on the cold air incursion and heat loss from the open door. In Table 5 , the symbol $G^{\prime}$ and $G^{\prime \prime}$ denote the total cold air incursion for the velocity, $v_{w 2}, 1 \mathrm{~m} / \mathrm{s}, 0.5 \mathrm{~m} / \mathrm{s}$, respectively. And, $\mathrm{Q}^{\prime}$ and $\mathrm{Q}^{\prime \prime}$ denote heat loss for the velocity, $\mathrm{v}_{\mathrm{w} 2}, 1 \mathrm{~m} / \mathrm{s}, 0.5 \mathrm{~m} / \mathrm{s}$, respectively. 
From the above calculating results, we can know that the average value of decreasing of cold air incursion, $\Delta \mathrm{G}_{\text {average }}$ is about $0.227 \mathrm{~m}^{3} / \mathrm{s}$, and the heat loss also reduces correspondingly, the average value, $\Delta \mathrm{Q}_{\text {average }}$ is about $0.293 \mathrm{~kW}$ when the velocity of cold air moving through the top section of the open door decreases, $\Delta \mathrm{v}_{\mathrm{w} 2}=0.5 \mathrm{~m} / \mathrm{s}$. The results also illustrate that the influence of velocity $\mathrm{v}_{\mathrm{w} 2}$ is smaller than the one of $\mathrm{v}_{\mathrm{w} 1}$. So we can conclude that the main cold air incursion and heat loss are caused by the cold air moving through the front section of the open door.

\section{Conclusions}

Based on the behavioral mathematical experiment of opening and closing the door, we can know that during the same period of time, $\Delta \tau, \mathrm{G} \times \mathrm{p}_{0}\left\langle\mathrm{G} \times \mathrm{p}_{30}\right.$ because of $\mathrm{p}_{0}>\mathrm{p}_{30}$ when the model is given "certain influences", obviously, its corresponding result is $\mathrm{Q} \times \mathrm{p}_{0}<\mathrm{Q} \times \mathrm{p}_{30}$, which also illustrate that the increasing of $\mathrm{p}_{0}$ is good for saving energy in short time.

\section{References}

[1] X.P. Li: Probability (Higher Education Press, China 1997). 